\title{
Pengaruh Tingkat Pemahaman Wajib Pajak, Kesadaran Wajib Pajak, dan Sanksi Pajak terhadap Kepatuhan Wajib Pajak
}

\author{
Ninik Khuzaimah ${ }^{\mathbf{1}}$, dan Sigit Hermawan ${ }^{{ }^{*}}$ \\ ${ }^{1,2}$ Universitas Muhammadiyah Sidoarjo
}

\begin{abstract}
This research aims to analyze the influence taxpayer level of understanding, taxpayer awareness, and tax penalties against tax compliance individual taxpayers conducting business ( Studies in KPP Pratama "X"). The analytical tool used is lists the questionnaire, data collection in the form of test validity and reliability testing. Hypothesis in this study is that there are influences the taxpayer level of understanding, taxpayer awareness, and tax penalties agains tax compliance individual taxpayer conducting business. To test this hypothesis used data analysis tools such as multiple linear regressio.

The results obtained by test validity indicates that all of the questions on the questionnaire is valid. To test reliability of all the variables declared reliable and based on hypothesis test based on the F test, $t$ test, and the coefficient of determination showed relationship between the taxpayer level of understanding, the taxpayer awareness, and tax penalties agains tax compliance individual taxpayer conducting business.
\end{abstract}

Keywords: Understanding, Awareness, Tax Penalties, and Compliance.

Tipe artikel: Empiris

\section{Pendahuluan}

\subsection{Latar Belakang Masalah}

Menurut Siahaan (2004:1) bahwa salah satu indikasi keberhasilan pemungutan pajak pada suatu negara adalah adanya kepatuhan masyarakat (wajib pajak) untuk membayar pajak terutang yang menjadi kewajibannya tepat pada waktunya. Akan tetapi, kondisi ideal ini tidak selalu terjadi, mengingat wajib pajak sangat sering berupaya untuk menghindari beban pajak yang dikenakan kepadanya.

Hal ini membuat mau tidak mau usaha untuk meningkatkan kesadaran masyarakat untuk membayar pajak juga harus ditingkatkan. Biasanya kesadaran sangat dipengaruhi oleh pemahaman seseorang tentang suatu permasalahan. Oleh karena itu, untuk meningkatkan kesadaran masyarakat dalam membayar pajak, diperlukan pemahaman bagi masyarakat mengapa mereka harus membayar pajak dan apa fungsi penerimaan negara dari sektor pajak (Siahaan, 2004:2).

Sementara itu, sistem perpajakan yang berlaku di Indonesia menuntut wajib pajak untuk memenuhi kewajibannya sendiri yaitu mendaftarkan diri, menghitung, membayar dan melapor. Oleh karena itu apabila kesadaran wajib pajak tinggi akan meningkatkan tingkat kepatuhan, sedangkan

\footnotetext{
${ }^{*}$ Penulis yang sesuai:

E-mail: sigithermawan@umsida.ac.id

Afiliasi: Universitas Muhammadiyah Gresik
} 
apabila wajib pajak memahami fungsi pajak akan meningkatkan tingkat kepatuhan karena sistem yang berlaku adalah Self Assessment System (Jotopurnomo dan Mangoting, 2013).

Hal yang terkait dengan perpajakan bahwa tingkat kepatuhan wajib pajak juga dapat dipengaruhi oleh persepsi wajib pajak tentang sanksi perpajakan. Terdapat undang-undang yang mengatur tentang ketentuan umum dan tata cara peraturan perpajakan. Agar peraturan perpajakan dipatuhi maka, harus ada sanksi perpajakan yang tegas bagi para pelanggarnya. Wajib pajak akan memenuhi kewajiban perpajakan bila memandang bahwa sanksi perpajakan akan lebih banyak merugikannya (Jatmiko, 2006:20).

Penelitian tentang kepatuhan wajib pajak telah dilakukan oleh beberapa peneliti. Namun sasaran penelitian sebelumnya lebih banyak pada sektor usaha kecil menengah dan wajib pajak badan (Arum dan Zulaikha, 2012:2). Rajif (2011) melakukan penelitian mengenai kepatuhan pajak pengusaha UKM. Sedangkan penelitian Utami (2012) melakukan penelitian terhadap tingkat kepatuhan wajib pajak badan.

Berdasarkan uraian di atas, masalah dalam penelitian ini adalah "apakah tingkat pemahaman wajib pajak, kesadaran wajib pajak, dan sanksi pajak berpengaruh secara parsial dan simultan terhadap kepatuhan wajib pajak orang pribadi yang melakukan kegiatan usaha di KPP Pratama "X" ?

\section{Landasan Teori}

\subsection{Tingkat Pemahaman Wajib Pajak}

Menurut Kamus Lengkap Bahasa Indonesia (1997:346), paham berarti faham, mengerti, maklum, mengetahui. Sedangkan pemahaman adalah proses, perbuatan, cara memahami atau memahamkan. Jadi pemahaman merupakan suatu proses dari berjalannya pengetahuan seseorang (Syahril, 2013).

\subsection{Kesadaran Wajib Pajak}

Kesadaran wajib pajak adalah pengetahuan wajib pajak bahwa perilaku wajib pajak diatur oleh ketentuan dan peraturan perpajakan, sehingga ada kecenderungan untuk mematuhi. Jadi tingkat kesadaran wajib pajak adalah tingkat pengetahuan wajib pajak bahwa perilakunya diatur oleh ketentuan dan peraturan perpajakan, sehingga ada kecenderungan dengan kemauan sendiri untuk mematuhi tanpa ada unsur paksaan (www.psychologymania).

\subsection{Sanksi Pajak}

Sanksi adalah suatu tindakan berupa hukuman yang diberikan kepada orang yang melanggar peraturan. Peraturan atau undang-undang merupakan rambu-rambu bagi seseorang untuk melakukan sesuatu mengenai apa yang harus dilakukan dan apa yang seharusnya tidak dilakukan. Sanksi diperlukan agar peraturan atau undang-undang tidak dilanggar (Arum dan Zulaikha, 2012:3).

\subsection{Kepatuhan Wajib Pajak}

Kepatuhan pajak adalah suatu keadaan saat wajib pajak paham atau berusaha untuk memahami semua ketentuan peraturan perundang undangan perpajakan, mengisi formulir pajak dengan lengkap dan jelas, menghitung jumlah pajak yang terutang dengan benar, dan membayar pajak yang terutang tepat pada waktunya (Jotopurnomo dan Mangoting, 2013).

\subsection{Wajib Pajak Orang Pribadi yang Melakukan Kegiatan Usaha}

Wajib pajak orang pribadi yang melakukan kegiatan usaha adalah mereka yang menyelenggarakan kegiatan usaha dan tidak terikat oleh suatu ikatan dengan pemberi kerja. Definisi menjalankan kegiatan usaha yang dimaksud adalah usaha apapun di berbagai bidang baik jasa, industri, perdagangan maupun yang lainnya (Arum dan Zulaikha, 2012:3). 


\subsection{Hipotesis}

$\mathrm{H}_{1}$ : Tingkat pemahaman wajib pajak berpengaruh terhadap kepatuhan wajib pajak

$\mathrm{H}_{2}$ : Kesadaran wajib pajak berpengaruh terhadap kepatuhan wajib pajak orang

$\mathrm{H}_{3}$ : Sanksi pajak berpengaruh terhadap kepatuhan wajib pajak orang pribadi

$\mathrm{H}_{4}$ : Tingkat pemahaman wajib pajak, kesadaran wajib pajak, dan sanksi pajak berpengaruh terhadap kepatuhan wajib pajak

\section{Metode Penelitian}

Penelitian ini menggunakan pendekatan kuantitatif inferensial. Kuantitatif inferensial (sering juga disebut statistik induktif atau statistik probabilitas) adalah teknik statistik yang digunakan untuk menganalisis data sampel dan hasilnya diberlakukan untuk populasi (Sugiyono, 2010: 207).

Variabel penelitian ini ada empat, yakni tingkat pemahaman wajib pajak (X1), kesadaran wajib pajak (X2), sanksi pajak (X3), dan kepatuhan wajib pajak (Y). Untuk pengukuran indikator keempat variabel tersebut menggunakan instrumen pertanyaan berskala Likert lima poin dari sangat tidak setuju (1) hingga sangat setuju (5). Berikut dijelaskan tentang variabel-variabel tersebut dan indikatornya.

a. Tingkat Pemahaman Wajib Pajak $\left(\mathrm{X}_{1}\right)$

Tingkat pemahaman wajib pajak dalam penelitian ini diartikan sebagai wajib pajak mengerti dan paham dalam hal menghitung, memperhitungkan, membayar, dan melaporkan pajak terutang. Dalam mengukur tingkat kepatuhan wajib pajak orang pribadi, pemahaman tentang perpajakan harus dimiliki oleh masing-masing wajib pajak orang pribadi. Dalam penelitian ini tingkat pemahaman wajib pajak diukur dengan indikator yang digunakan Siahaan (2004:23), Supadmi dan Andryani (2010), yakni: (1) Menghitung, (2) Memperhitungkan, (3) Membayar, (4) Melapor pajak terutang.

b. Kesadaran Wajib Pajak $\left(\mathrm{X}_{2}\right)$

Adanya memiliki kesadaran pajak tinggi akan mengerti fungsi dan manfaat pajak, baik mengerti untuk masyarakat maupun diri pribadi, sehingga wajib pajak akan sukarela membayar pajak tanpa paksaan (Musyarofah dan Purnomo, 2008). Dalam penelitian ini, kesadaran wajib pajak diukur dengan indikator yang digunakan Irianto (2005:27), dan Rahmawaty, dkk (2011), yakni: (1) Pajak bentuk partisipasi dalam menunjang pembangunan negara; (2) Penundaan pembayaran pajak sangat merugikan negara; (3) Pajak ditetapkan undang-undang; (4) Tidak membayar pajak yang sesuai merugikan negara.

c. Sanksi Pajak $\left(\mathbf{X}_{3}\right)$

Sanksi perpajakan merupakan jaminan bahwa ketentuan peraturan perundang-undangan perpajakan (norma perpajakan) akan dituruti/ditaati/dipatuhi. Atau bisa dengan kata lain sanksi perpajakan merupakan alat pencegah (preventif) agar wajib pajak tidak melanggar norma perpajakan (Suandy, 2011:L-1). Dalam penelitian ini sanksi pajak diukur dengan indikator yang digunakan Suandy (2011:L-1), Muliari dan Setiawan (2011), yakni: (1) Sanksi pidana; (2) Sanksi administrasi; (3) Sanksi merupakan sarana untuk mendidik; (4) Sanksi pajak dikenakan kepada pelanggarnya.

d. Kepatuhan Wajib Pajak

Kepatuhan merupakan kepatuhan wajib pajak terhadap peraturan atau undang-undang perpajakan (Arum dan Zulaikha, 2012). Dalam penelitian ini kepatuhan wajib pajak diukur dengan indikator yang digunakan Jatmiko (2006:17), Jotopurnomo dan Mangoting (2013) yakni: (1) Paham UU perpajakan; (2) Mengisi formulir pajak; (3) Menghitung pajak; (4) Membayar pajak tepat waktu.

Tabel 1

Ringkasan Indikator Variabel

\begin{tabular}{|c|c|c|c|}
\hline Variabel & Indikator & Pernyataan & Sumber \\
\hline \multirow{4}{*}{$\begin{array}{l}\text { Tingkat } \\
\text { Pemahaman } \\
\text { (X1) }\end{array}$} & 1. Menghitung & 1. Sebagai wajib pajak, saya & Siahaan (2004:23), \\
\hline & & menghitung sendiri pajak ter & Supadmi dan \\
\hline & & $\begin{array}{l}\text { berdasarkan ketentuan peraturan } \\
\text { perpajakan yang berlaku }\end{array}$ & Andryani (2010) \\
\hline & $\begin{array}{l}\text { 2. Memperhitung } \\
\text { kan }\end{array}$ & $\begin{array}{l}\text { 2. Sebagai wajib pajak, saya mampu } \\
\text { memperhitungkan besarnya pajak } \\
\text { penghasilan yang harus dibavar }\end{array}$ & \\
\hline
\end{tabular}




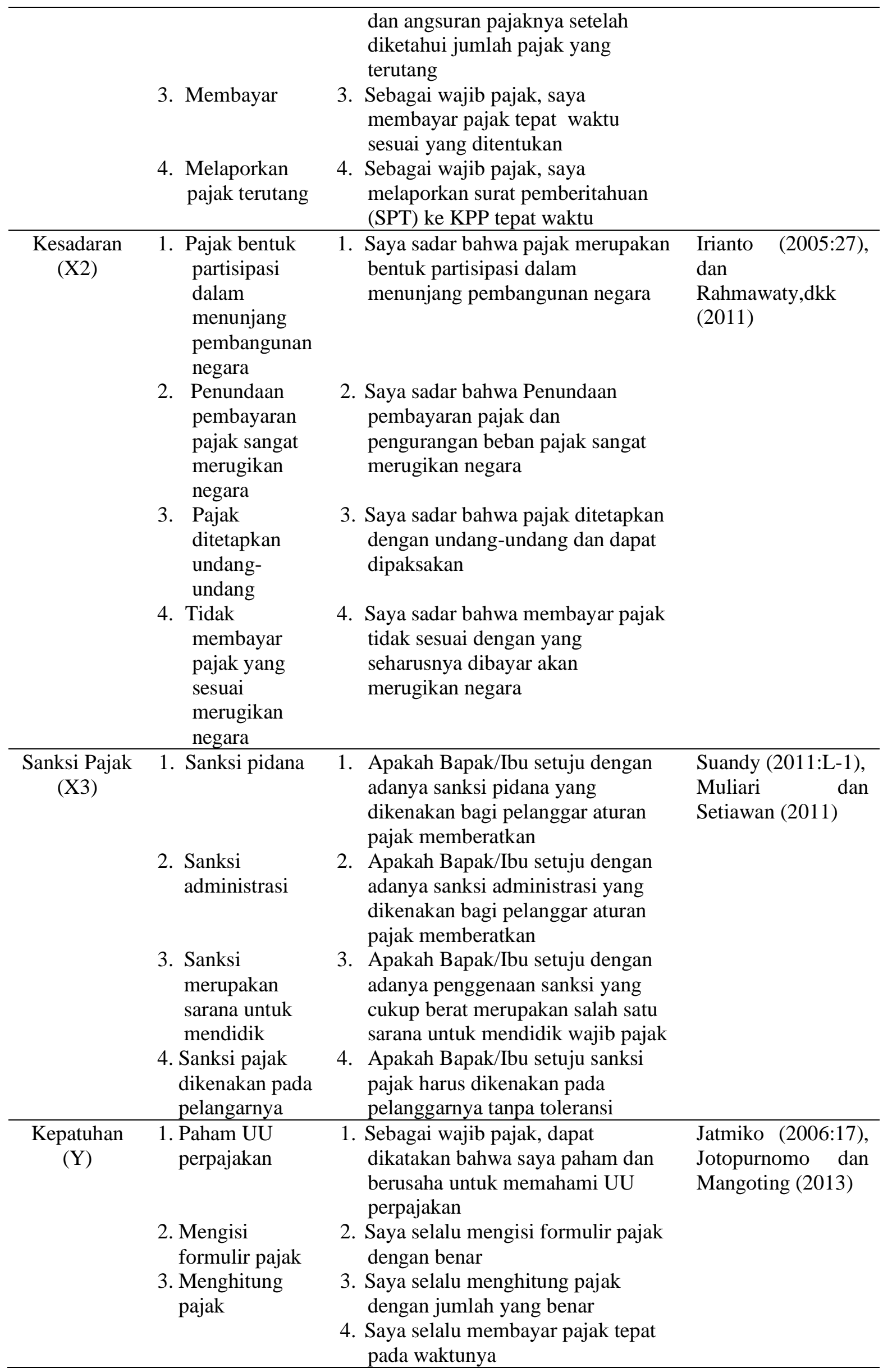




\begin{tabular}{l}
$\begin{array}{l}\text { 4. Membayar } \\
\text { pajak tepat } \\
\text { waktu }\end{array}$ \\
\hline
\end{tabular}

Sumber: Data diolah

Penelitian ini dilaksanakan di KPP Pratama "X", dengan responden wajib pajak orang pribadi yang melakukan kegiatan usaha. Berdasarkan data dari KPP Pratama " $X$ ", tercatat sebanyak 4.445 wajib pajak orang pribadi yang melakukan kegiatan usaha. Penentuan sampel dilakukan dengan metode random sampling dengan menggunakan rumus Slovin dengan margin of error $10 \%$ adalah:

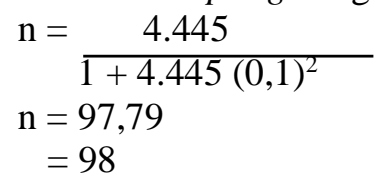

Berdasarkan perhitungan diatas, maka jumlah sampel yang diambil dalam penelitian ini adalah sebanyak 98 wajib pajak orang pribadi yang melakukan kegiatan usaha. Jenis data yang digunakan dalam penelitian ini, yaitu data primer. Data primer yaitu data yang diperoleh secara langsung dari sumber aslinya. Sumber data primer pada penelitian ini diperoleh langsung dari wajib pajak orang pribadi yang melakukan kegiatan usaha yang berada di KPP Pratama "X". Data ini berupa kuesioner yang telah diisi oleh wajib pajak yang menjadi responden dalam penelitian ini.

Teknik pengumpulan data dalam penelitian ini diperoleh dengan menggunakan metode survey yaitu kuesioner secara personal. Sejumlah pernyataan diajukan kepada responden dan kemudian responden diminta menjawab sesuai dengan pendapat mereka. Untuk mengukur pendapat responden digunakan skala likert lima angka yaitu mulai angka 5 untuk pendapat sangat setuju (SS) dan angka 1 untuk sangat tidak setuju (STS).

\section{Hasil Analisis dan Pembahasan}

\subsection{Statistik Deskriptif}

Analisis data dilakukan terhadap 98 jawaban responden yang memenuhi kriteria untuk pengolahan data. Analisis ini menjelaskan karakteristik target populasi terutama mencakup mean, nilai minimum, nilai maksimum, serta standar deviasi.

\section{Tabel 2}

Hasil Uji Statistik Deskriptif Descriptive Statistics

\begin{tabular}{|l|r|r|r|r|r|}
\hline & N & Minimum & Maximum & Mean & Std. Deviation \\
\hline pemahaman.x1 & 98 & 11 & 20 & 16.56 & 1.990 \\
kesadaran.x2 & 98 & 11 & 20 & 15.92 & 2.009 \\
sanksi.x3 & 98 & 10 & 20 & 15.66 & 2.046 \\
kepatuhan.y & 98 & 11 & 20 & 16.14 & 2.051 \\
Valid N & 98 & & & & \\
(listwise) & & & & & \\
\hline
\end{tabular}

Sumber: Data diolah

\subsection{Uji Validitas dan Reliabilitas}

Uji validitas merupakan suatu ukuran yang menunjukkan tingkat keandalan atau keabsahan suatu alat ukur. Validitas digunakan untuk mengetahui kelayakan butir-butir dalam suatu daftar (konstruk) pertanyaan dalam mendefinisikan suatu variabel. Pengujian validitas dilakukan dengan menggunakan rumus korelasi. Dapat dianggap valid jika korelasi melebihi 0,3 (Sunjoyo dkk, 2013:39).

\section{Tabel 3}


Uji Validitas Instrumen Tingkat Pemahaman WP $\left(\mathbf{X}_{1}\right)$

\begin{tabular}{ccc}
\hline Indikator & Pearson Correlation & Keterangan \\
\hline $\mathrm{X} 1.1$ & .641 & Valid \\
\hline $\mathrm{X} 1.2$ & .758 & Valid \\
\hline $\mathrm{X} 1.3$ & .715 & Valid \\
\hline $\mathrm{X} 1.4$ & .716 & Valid \\
\hline
\end{tabular}

Sumber: Data diolah

Tabel 4

Uji Validitas Instrumen Kesadaran WP $\left(\mathbf{X}_{2}\right)$

\begin{tabular}{ccc}
\hline Indikator & Pearson Correlation & Keterangan \\
\hline X2.1 & .575 & Valid \\
\hline X2.2 & .751 & Valid \\
\hline X2.3 & .732 & Valid \\
\hline X2.4 & .780 & Valid \\
\hline
\end{tabular}

Sumber: Data diolah

Tabel 5

Uji Validitas Instrumen Sanksi Pajak $\left(X_{3}\right)$

\begin{tabular}{ccc}
\hline Indikator & Pearson Correlation & Keterangan \\
\hline X3.1 & .809 & Valid \\
\hline X3.2 & .751 & Valid \\
\hline X3.3 & .529 & Valid \\
\hline X3.4 & .757 & Valid \\
\hline
\end{tabular}

Sumber: Data diolah

Tabel 6

Uji Validitas Instrumen Kepatuhan WP (Y)

\begin{tabular}{ccc}
\hline Indikator & Pearson Correlation & Keterangan \\
\hline Y.1 & .723 & Valid \\
\hline Y.2 & .787 & Valid \\
\hline Y.3 & .753 & Valid \\
\hline Y.4 & .639 & Valid \\
\hline
\end{tabular}

Sumber: Data diolah

Tabel 3, 4, 5, dan 6 terlihat bahwa semua butir pernyataan untuk variabel tingkat pemahaman wajib pajak $\left(\mathrm{X}_{1}\right)$, kesadaran wajib pajak $\left(\mathrm{X}_{2}\right)$, sanksi pajak $\left(\mathrm{X}_{3}\right)$, kepatuhan wajib pajak $(\mathrm{Y})$ berada pada tingkat signifikansi yaitu diatas 0,3 maka dapat disimpulkan bahwa pernyataan dalam penelitian ini valid. Hal ini berarti bahwa semua item pernyataan yang digunakan dalam penelitian ini mampu mengungkapkan sesuatu yang diukur pada kuesioner tersebut.

Reliabilitas merupakan indeks yang menunjukkan sejauh mana suatu alat pengukur dapat dipercaya atau dapat diandalkan. Setiap alat pengukuran seharusnya memiliki kemampuan untuk memberikan hasil pengukuran relatif konsisten dari waktu ke waktu. Pengujian reliabilitas dalam penelitian ini adalah dengan menggunakan rumus alpha. Suatu konstruk dikatakan reliabel jika memiliki Cronbach Alpha > 0,60 (Sunjoyo dkk, 2013:41).

Tabel 7 menunjukkan hasil uji reliabilitas instrumen terhadap 98 responden yang terdaftar di KPP Pratama "X".

Tabel 7

Uji Reliabilitas

\begin{tabular}{cccc}
\hline Indikator & Cronbach Alpha & N of Item & Keterangan \\
\hline Tingkat & .660 & 4 & Reliabel \\
pemahaman & & & \\
WP $\left(\mathrm{X}_{1}\right)$ & & 4 & Reliabel \\
\hline $\begin{array}{c}\text { Kesadaran WP } \\
\left(\mathrm{X}_{2}\right)\end{array}$ & .638 & & \\
\hline
\end{tabular}


Ninik Khuzaimah dan Sigit Hermawan

\begin{tabular}{cccc}
\hline $\begin{array}{c}\text { Sanksi Pajak } \\
\left(\mathrm{X}_{3}\right)\end{array}$ & .662 & 4 & Reliabel \\
\hline $\begin{array}{c}\text { Kepatuhan WP } \\
(\mathrm{Y})\end{array}$ & .672 & 4 & Reliabel \\
\hline
\end{tabular}

Sumber: Data diolah

Berdasarkan hasil uji statistik pada tabel diatas yaitu tabel menunjukkan bahwa pernyataan dalam kuesioner ini reliabel karena mempunyai nilai Cronbach Alpha >0,60. Hal ini menunjukkan bahwa setiap item pernyataan yang digunakan akan mampu memperoleh data yang konsisten yang berarti bila pernyataan itu diajukan kembali akan diperoleh jawaban yang relatif sama dengan jawaban sebelumnya.

\subsection{Uji Normalitas Data}

Uji normalitas dilakukan untuk melihat apakah nilai residual terdistribusi normal atau tidak. Model regresi yang baik adalah memiliki nilai residual yang terdistribusi normal (Sunjoyo dkk, 2013:60). uji normalitas data dilakukan dengan menggunakan Normal Probability Plot (Normal P-Plot).

\section{Normal P-P Plot of Regression Standardized Residual}

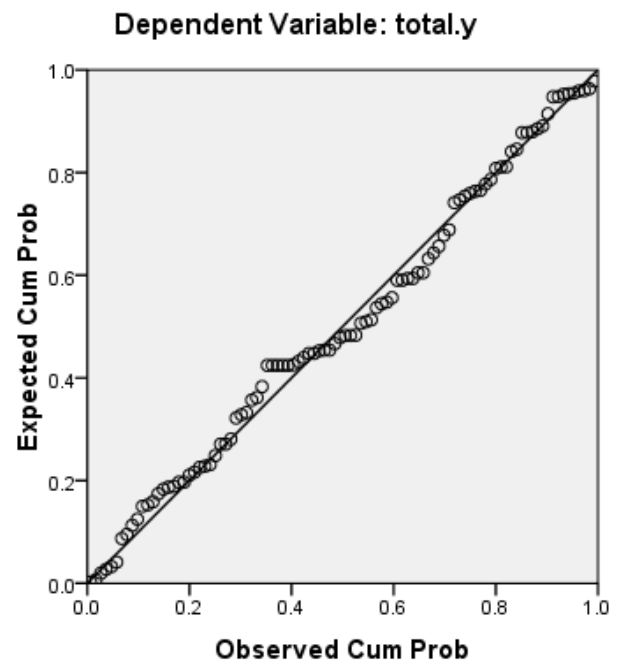

Sumber: Data diolah

Berdasarkan grafik normal P-Plot pada gambar menunjukkan bahwa model regresi layak dipakai dalam penelitian ini karena pada grafik normal P-Plot terlihat titik-titik menyebar disekitar garis diagonal sehingga memenuhi asumsi normalitas.

\subsection{Uji Multikolinieritas}

Uji multikolinieritas dilakukan untuk melihat ada atau tidaknya korelasi yang tinggi antara variabel-variabel bebas dalam suatu model regresi linier berganda.

\section{Tabel 8}

\section{Hasil Uji Multikolinieritas}

Coefficients $^{a}$ 


\begin{tabular}{|l|r|r|}
\hline \multirow{2}{*}{\multicolumn{1}{|c|}{ Model }} & \multicolumn{2}{|c|}{ Collinearity Statistics } \\
\cline { 2 - 3 } & Tolerance & \multicolumn{2}{|c|}{ VIF } \\
\hline 1(Constant) & .704 & 1.421 \\
total.x1 & .689 & 1.452 \\
total.x2 & .795 & 1.258 \\
total.x3 & & \\
\hline
\end{tabular}

a. Dependent Variable: total.y

Sumber: Data diolah

Multikolinieritas diukur melalui nilai Variance Inflaction Factor (VIF). Apabila nilai VIF > 10 dikatakan mengalami multikolinieritas. Pada data diatas dapat disimpulkan bahwa persamaan regresi tidak terdapat masalah multikolinearitas karena nilai tolerance di atas 0.10 dan nilai VIF (Variance Inflation Factor) dibawah 10.

\subsection{Uji Heteroskedastisitas}

Uji Heteroskedastisitas dilakukan untuk melihat apakah terdapat ketidaksamaan varians dari residual satu ke pengamatan ke pengamatan yang lain.

\section{Scatterplot}

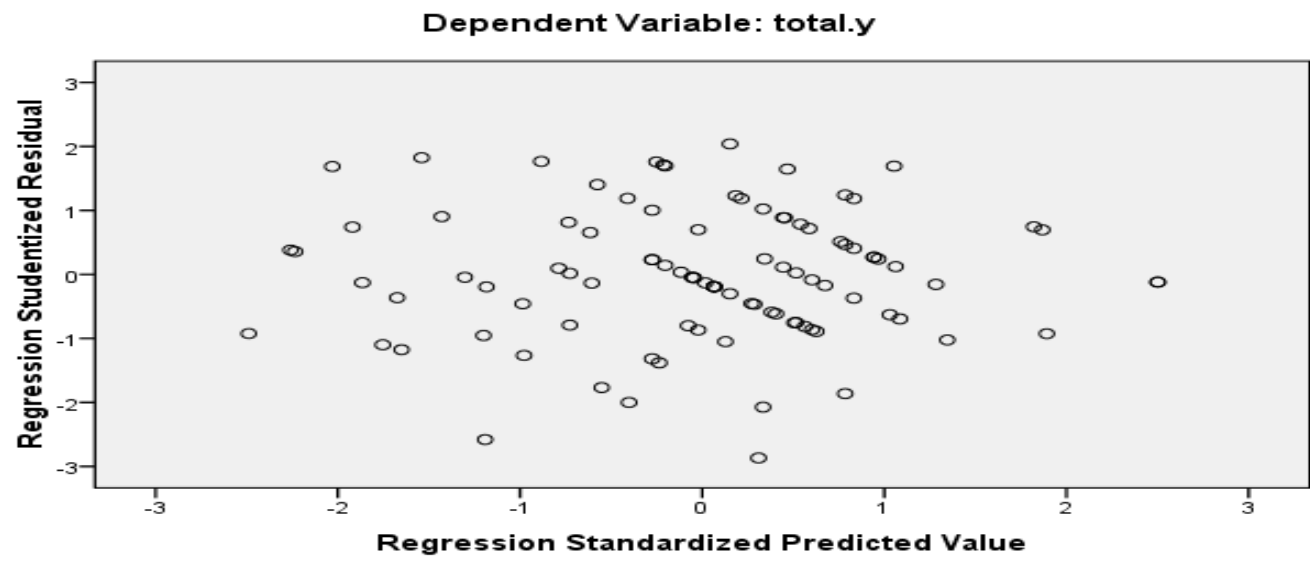

Sumber: Data diolah

Berdasarkan grafik scatterplot pada gambar terlihat bahwa titik-titik menyebar secara acak serta tersebar baik diatas maupun dibawah. Hal ini dapat disimpulkan bahwa tidak terjadi heteroskedastisitas pada model regresi. 


\section{Tabel 9}

Hasil Uji Regresi Linier Berganda

\section{Coefficients $^{\mathrm{a}}$}

\begin{tabular}{|c|c|c|c|c|c|}
\hline \multirow{2}{*}{\multicolumn{2}{|c|}{ Model }} & \multicolumn{2}{|c|}{ Unstandardized Coefficients } & \multirow{2}{*}{$\begin{array}{c}\begin{array}{c}\text { Standardized } \\
\text { Coefficients }\end{array} \\
\text { Beta }\end{array}$} & \\
\hline & & $\mathrm{B}$ & Std. Error & & \\
\hline 1 & (Constant) & .638 & 1.343 & & \\
\hline & total.x1 & .177 & .079 & & 172 \\
\hline & total.x2 & .254 & .079 & & 248 \\
\hline & total.x3 & .545 & .072 & & 543 \\
\hline
\end{tabular}

a. Dependent Variable: total.y

Sumber: Data diolah

Berdasarkan tabel diatas diketahui bahwa nilai koefisien dari persamaan regresi. Dari output didapatkan model persamaan regresi:

$$
\begin{aligned}
& Y=\alpha+\beta_{1} X_{1}+\beta_{2} X_{2}+\beta_{3} X_{3}+e \\
& Y=0,638+0,177 X_{1}+0,254 X_{2}+0,545 X_{3}+e
\end{aligned}
$$

\subsection{Koefisien Determinasi $\left(R^{2}\right)$}

Koefisien determinasi $\left(\mathrm{R}^{2}\right)$ bertujuan untuk mengetahui seberapa besar kemampuan variabel independen menjelaskan variabel dependen.

Tabel 10

Hasil Uji Koefisien Determinasi $\left(\mathbf{R}^{2}\right)$

Model Summary ${ }^{b}$

\begin{tabular}{|l|r|r|r|r|}
\hline Model & R & R Square & $\begin{array}{c}\text { Adjusted R } \\
\text { Square }\end{array}$ & $\begin{array}{c}\text { Std. Error of the } \\
\text { Estimate }\end{array}$ \\
\hline 1 & $.781^{\mathrm{a}}$ & .611 & .598 & 1.300 \\
\hline
\end{tabular}

a. Predictors: (Constant), total.x3, total.x1, total.x2

b. Dependent Variable: total.y

Sumber: Data diolah

Berdasarkan tabel 10 Model Summary, diperoleh nilai adjusted $\mathrm{R}^{2}$ sebesar 0,598. Hal ini menunjukkan bahwa persentase sumbangan pengaruh variabel independen (tingkat pemahaman wajib pajak $\left(\mathrm{X}_{1}\right)$, kesadaran wajib pajak $\left(\mathrm{X}_{2}\right)$, dan sanksi pajak $\left(\mathrm{X}_{3}\right)$ ) terhadap variabel dependen ( kepatuhan wajib pajak orang pribadi yang melakukan kegiatan usaha $(\mathrm{Y})$ ) sebesar 59,8\%. Atau variasi variabel independen yang digunakan dalam model (tingkat pemahaman wajib pajak $\left(\mathrm{X}_{1}\right)$, kesadaran wajib pajak $\left(\mathrm{X}_{2}\right)$, dan sanksi pajak $\left(\mathrm{X}_{3}\right)$ ) Mampu menjelaskan sebesar 59,8\% variansi variabel dependen ( kepatuhan wajib pajak orang pribadi yang melakukan kegiatan usaha (Y)). Sedangkan sisanya sebesar 40,2\% dipengaruhi atau dijelaskan oleh variabel lain yang tidak dimasukkan dalam model penelitian ini. 


\subsection{Hasil Uji Hipotesis}

\subsubsection{Uji t}

Uji parsial digunakan untuk mengetahui pengaruh masing-masing variabel independen terhadap variabel dependen jika nilai $\mathrm{t}_{\text {hitung }}>\mathrm{t}$ tabel atau nilai signifikan $<$ alpha maka dikatakan mendukung hipotesis, sebaliknya apabila $\mathrm{t}_{\text {hitung }}<\mathrm{t}$ tabel atau nilai signifikan $>$ alpha maka dikatakan menolak hipotesis. Dengan tingkat signifikan 0,05 $(\mathrm{a}=5 \%)$. Hasil uji t dapat dilihat pada tabel 11:

\section{Tabel 11}

\section{Hasil Uji t}

\section{Coefficients $^{\mathbf{a}}$}

\begin{tabular}{|c|c|c|c|c|c|c|}
\hline \multirow{2}{*}{\multicolumn{2}{|c|}{ Model }} & \multicolumn{2}{|c|}{ Unstandardized Coefficients } & \multirow{2}{*}{$\begin{array}{c}\text { Standardized } \\
\text { Coefficients }\end{array}$} & \multirow[b]{2}{*}{$\mathrm{T}$} & \multirow[b]{2}{*}{ Sig. } \\
\hline & & B & Std. Error & & & \\
\hline \multirow[t]{4}{*}{1} & (Constant) & .638 & 1.343 & & .475 & .636 \\
\hline & total.x 1 & .177 & .079 & .172 & 2.240 & .027 \\
\hline & total.x2 & .254 & .079 & .248 & 3.203 & .002 \\
\hline & total.x3 & .545 & .072 & .543 & 7.526 & .000 \\
\hline
\end{tabular}

a. Dependent Variable: total.y

Sumber: Data diolah

Hipotesis pertama $\left(\mathrm{H}_{1}\right)$ menyatakan bahwa tingkat pemahaman wajib pajak $\left(\mathrm{X}_{1}\right)$ berpengaruh terhadap kepatuhan wajib pajak orang pribadi yang melakukan kegiatan usaha. Berdasarkan tabel 11 tentang hasil uji $\mathrm{t}\left(\mathrm{X}_{1}\right)$ menyatakan bahwa $\mathrm{t}$ hitung sebesar 2,240. Nilai ini lebih besar dari $\mathrm{t}$ tabel sebesar 1,66 atau 2,240 > 1,66. Demikian pula diperoleh nilai signifikan sebesar 0,027 < 0,05 yang berarti terdapat pengaruh. Kesimpulannya bahwa $\mathbf{H}_{1}$ diterima.

Hipotesis kedua $\left(\mathrm{H}_{2}\right)$ menyatakan bahwa kesadaran wajib pajak $\left(\mathrm{X}_{2}\right)$ berpengaruh terhadap kepatuhan wajib pajak orang pribadi yang melakukan kegiatan usaha. Berdasarkan tabel 4.13 tentang hasil uji $\mathrm{t}\left(\mathrm{X}_{2}\right)$ menyatakan bahwa $\mathrm{t}$ hitung sebesar 3,203. Nilai ini lebih besar dari $\mathrm{t}$ tabel sebesar 1,66 atau $3,203>1,66$. Demikian juga hasil signifikan menunjukkan nilai $0,002<0,05$ yang berarti terdapat pengaruh. Kesimpulannya bahwa $\mathbf{H}_{2}$ diterima.

Hipotesis ketiga $\left(\mathrm{H}_{3}\right)$ menyatakan bahwa sanksi pajak $\left(\mathrm{X}_{3}\right)$ berpengaruh terhadap kepatuhan wajib pajak orang pribadi yang melakukan kegiatan usaha. Berdasarkan tabel 4.13 tentang hasil uji $\mathrm{t}\left(\mathrm{X}_{3}\right)$

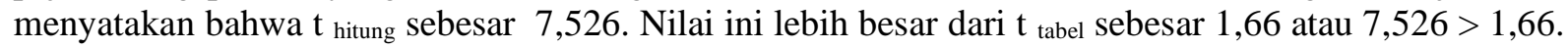
Demikian juga hasil signifikan menunjukkan nilai $0,000<0,05$ yang berarti terdapat pengaruh. Kesimpulannya bahwa $\mathrm{H}_{3}$ diterima.

\subsubsection{Uji F}

Uji pengaruh simultan digunakan untuk mengetahui apakah variabel independen secara bersamasama atau simultan mempengaruhi variabel dependen. Jika nilai $\mathrm{F}_{\text {hitung }}>\mathrm{F}_{\text {tabel }}$ atau nilai signifikan < alpha maka dikatakan mempengaruhi hipotesis. Dengan tingkat signifikan $0,05(\mathrm{a}=5 \%)$. Hasil uji F dapat dilihat pada tabel 12:

\section{Tabel 12}

Hasil Uji F 
ANOVA $^{b}$

\begin{tabular}{|c|c|c|c|c|c|c|}
\hline \multicolumn{2}{|c|}{ Model } & $\begin{array}{l}\text { Sum of } \\
\text { Squares }\end{array}$ & Df & Mean Square & $\mathrm{F}$ & Sig. \\
\hline \multirow[t]{3}{*}{1} & Regression & 249.100 & 3 & 83.033 & 49.120 & $.000^{\mathrm{a}}$ \\
\hline & Residual & 158.900 & 94 & 1.690 & & \\
\hline & Total & 408.000 & 97 & & & \\
\hline
\end{tabular}

a. Predictors: (Constant), total.x3, total.x1, total.x2

b. Dependent Variable: total.y

Sumber: Data diolah

Hipotesis keempat $\left(\mathrm{H}_{4}\right)$ menyatakan bahwa tingkat pemahaman wajib pajak $\left(\mathrm{X}_{1}\right)$, kesadaran wajib pajak $\left(\mathrm{X}_{2}\right)$, dan sanksi pajak $\left(\mathrm{X}_{3}\right)$ berpengaruh terhadap kepatuhan wajib pajak orang pribadi yang melakukan kegiatan usaha. Berdasarkan tabel 4.14 tentang hasil uji $\mathrm{F}$ menyatakan bahwa $\mathrm{F}$ hitung sebesar 49,120. Nilai ini lebih besar dari $\mathrm{F}_{\text {tabel }}$ sebesar 2,70 atau 49,120>2,70. Demikian pula diperoleh nilai signifikan sebesar $0,000<0,05$ yang berarti terdapat pengaruh. Kesimpulannya bahwa $\mathbf{H}_{\mathbf{4}}$ diterima. Hasil uji hipotesis menunjukkan bahwa tingkat pemahaman wajib pajak, kesadaran wajib pajak, dan sanksi pajak berpengaruh terhadap kepatuhan wajib pajak orang pribadi yang melakukan kegiatan usaha.

\section{Simpulan dan Saran}

Penelitian ini bertujuan untuk menguji pengaruh tingkat pemahaman wajib pajak, kesadaran wajib pajak, dan sanksi pajak terhadap kepatuhan wajib pajak orang pribadi yang melakukan kegiatan usaha. Responden dalam penelitian ini berjumlah 98 wajib pajak orang pribadi yang melakukan kegiatan usaha yang terdaftar di KPP Pratama "X".

Berdasarkan dari hasil uji t menunjukkan bahwa Variabel tingkat pemahaman wajib pajak $\left(\mathrm{X}_{1}\right)$, kesadaran wajib pajak $\left(\mathrm{X}_{2}\right)$, dan sanksi pajak $\left(\mathrm{X}_{3}\right)$ secara parsial berpengaruh terhadap variabel kepatuhan wajib pajak orang pribadi yang melakukan kegiatan usaha. Begitu pula dari hasil uji F secara simultan terdapat pengaruh dari variabel tingkat pemahaman wajib pajak, kesadaran wajib pajak, dan sanksi pajak terhadap kepatuhan wajib pajak orang pribadi yang melakukan kegiatan usaha.

Saran dalam penelitian ini adalah: (1) Penelitian ini menggunakan 3 variabel independen yang mempengaruhi kepatuhan wajib pajak orang pribadi yang melakukan kegiatan usaha, sehingga penulis mengharapkan partisipasi aktif peneliti berikutnya untuk meneliti variabel independen lain yang dapat mempengaruhi kepatuhan wajib pajak orang pribadi yang melakukan kegiatan usaha seperti variabel tingkat kepuasan pelayanan, keadilan perpajakan, dan lain-lain. (2) Penelitian ini hanya menggunakan sampel wajib pajak orang pribadi yang melakukan kegiatan usaha yang terdaftar di KPP Pratama "X". Sehingga diharapkan penelitian selanjutnya dapat memperluas agar diperoleh hasil penelitian yang tingkat generalisasinya lebih tinggi. (3) Penelitian ini hanya menggunakan sampel 98 responden. Sehingga diharapkan penelitian selanjutnya dapat menggunakan lebih banyak sampel untuk dapat memperoleh hasil yang lebih akurat mengenai faktor-faktor yang mempengaruhi kepatuhan wajib pajak orang pribadi yang melakukan kegiatan usaha.

\section{DAFTAR PUSTAKA}

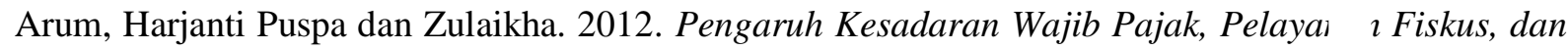
Sanksi Pajak Terhadap Kepatuhan Wajib Pajak Orang Pribadi yang Melakukan Kegiatan Usaha dan Pekerjaan Bebas. Journal Undip Vol 1 No 1. Universitas Diponegoro.

Berutu, Dian Anggraeni dan Harto, Puji. 2012. Persepsi keadilan Pajak Terhadap Perilaku Kepatuhan Wajib Pajak Orang Pribadi (WPOP). Journal Undip Vol 2 No 2. Universitas Diponegoro.

Harahap, Abdul Asri. 2004. Paradigma Baru Perpajakan Indonesia. Integrita Dinamika Press. Jakarta. 
Ikatan Akuntan Indonesia (IAI). 2013. Modul Pelatihan Pajak Terapan Brevet A \& B Terpadu. Cetakan 27. Jakarta Pusat.

Ikatan Akuntan Indonesia (IAI). 2013. Susunan Dalam Satu NaskahUndang-Undang Perpajakan. Cetakan 26. Jakarta Pusat.

Irianto, Slamet Edi. 2005. Politik Perpajakan Membangun Demokrasi Negara. UII Press. Yogyakarta.

Jatmiko, Agus Nugroho. 2006. Pengaruh Sikap Wajib Pajak Pada Pelaksanaan Sanksi Denda, Pelayanan Fiskus, dan Kesadaran Perpajakan Terhadap Kepatuhan Wajib Pajak (Studi Empiris Terhadap Wajib Pajak Orang Pribadi di Kota Semarang). Tesis tidak diterbitkan. Program Pasca Sarjana Universitas Diponegoro.

Jotopurnomo, Cindy dan Mangoting, Yenni. 2013. Pengaruh Kesadaran Wajib Pajak, Kualitas Pelayanan Fiskus, Sanksi Perpajakan, Lingkungan Wajib Pajak Berada terhadap Kepatuhan Wajib Pajak Orang Pribadi di Surabaya. Tax \& Accounting Review Vol 1 No 1. Universitas Kristen Petra.

Kesadaran Wajib Pajak (http://www.psychologymania.com, diakses 25 Februari 2014)

Komaruddin dan Komaruddin, Yooke Tjuparmah S. 2007. Kamus Karya Tulis Ilmiah. Edisi ke satu, Cetakakan ke empat. PT Bumi Aksara. Jakarta.

Muliari, Ni Ketut dan Setiawan, Putu Ery. (2011). Pengaruh Persepsi Tentang Sanksi Perpajakan dan Kesadaran Wajib Pajak Pada Kepatuhan Pelaporan Wajib Pajak Orang Pribadi di KPP Denpasar Timur. Jurnal akuntasi bisnis Vol.6. Universitas Udayana.

Musyarofah, Siti dan Purnomo, Adi. 2008. Pengaruh Kesadaran dan Persepsi Tentang Sanksi dan Hasrat Membayar Pajak Terhadap Kepatuhan Wajib Pajak. Jurnal akuntansi, manajemen bisnis dan sektor publik (JAMBSP) Vol 5 No 1. Universitas Trunojoyo.

Pembukuan dan Pencatatan Bagi Wajib Pajak, (http://www.pajak.go.id, diakses 28 Januari 2014).

Rahmawaty, Endang Surasetyo Ningsih, dan Wida Fadhlia. 2011. Fator-Faktor Yang Mempengaruhi Kemauan Membayar Pajak. Jurnal Telaah \& Riset Akuntansi Vol 4 No 2.Universitas Syiah Kuala.

Rajif, Mohammad. 2011. Pengaruh Pemahaman, Kualitas Pelayanan, dan Ketegasan Sanksi Perpajakan Terhadap Kepatuhan Pajak Pengusaha UKM di Daerah Cirebon. Universitas Gunadarma. Jakarta.

Siahaan, Mariohat. 2004. Utang Pajak, Pemenuhan Kewajiban dan Penagihan Pajak dengan Surat Paksa. PT Raja Grafindo. Jakarta.

Suandy, Erly. 2011. Perencanaan Pajak. Edisi 5, Salemba Empat. Jakarta.

Sugiyono. 2010. Metode Penelitian Bisnis (Pendekatan Kuantitatif, Kualitatif, dan R\&D). Cetakan ke 15. Alfabeta. Bandung.

Sunjoyo, Rony Setiawan, Verani Carolina, Nonie Magdalena, dan Albert Kurniawan. 2013. Aplkasi SPSS Untuk Smart Riset. Alfabeta. Bandung.

Supadmi, Ni Luh dan Andriyani, Wiwik. 2010. Analisis Tingkat Pemahaman Wajib Pajak Orang Pribadi Pada Pelaksanaan Self Assesment System Dalam Melaksanakan Kewajiban Perpajakan. Jurnal Akuntansi dan Bisnis. Universitas Udayana.

Susanto, Herry. 2012, 9 Januari. Membangun Kesadaran Dan Kepedulian Sukarela Wajib Pajak (http://www.pajak.go.id, diakses 25 Februari 2014).

Syahril, Farid. 2013. Pengaruh Tingkat Pemahaman Wajib Pajak dan Kualitas Pelayanan Fiskus TerhadapTingkat Kepatuhan Wajib Pajak PPh Orang Pribadi. Universitas Negeri Padang. 
Tiraada, Tryana A.M. 2013. Kesadaran Perpajakan, Sanksi Pajak, Sikap Fiskus Terhadap Kepatuhan WPOP di Kabupaten Minahasa Selatan. Jurnal EMBA Vol 1 No 3. Universitas Sam Ratulangi.

Utami, Kharina. 2012. Pengaruh Pemahaman Ketentuan dan Akuntansi Perpajakan Terhadap Tingkat Kepatuhan Wajib Pajak Badan. Universitas Siliwangi. Tasikmalaya.

Yasyin, Sulchan. 1997. Kamus Lengkap Bahasa Indonesia.Amanah. Surabaya. 